\title{
Highly attractive models in advertising: What causes negative affect?
}

\author{
- Nguyen Hoang Sinh \\ Ho Chi Minh Open University \\ (Manuscript Received on December $1^{\text {st }} 2012$, Manuscript Revised on October $9^{\text {th }} 2013$ )
}

\begin{abstract}
:
Highly attractive models (HAMs) have been popularly used in advertising to exert psychological impacts on the message receiver in the hope of increasing advertisement's effectiveness. The marketing literature is replete with evidence of the positive effects of using HAMs. However, support for their effectiveness is somewhat conflicted. The research attempts to add to the body of general knowledge, specifically through exploring the impact of individual difference variables (model characteristics, product types, comparison motives and culture) on negative effects. This study also investigates whether advertising skepticism determined by culture has an impact on negative effects as a result
\end{abstract}

of a HAM comparison. The methodology uses a 3 [beauty types] $x 2$ [product types] $x$ 2 [comparison motives] between-subjects experimental design. Respondents for the main study are female students across cultures from international programs and universities in Vietnam. The results supported all hypotheses; except product types shown having no impact on negative effects. The research also confirmed there are interrelationships between culture and skepticism. These findings have implications regarding the potentially negative influence of advertising including HAMs for practitioners, academics and public policy makers.

Keywords: Negative affect, beauty type, product type, comparison motive, across-culture, advertising skepticism

\section{INTRODUCTION}

Highly attractive models (HAMs) are deemed to be "haunting images of perfection" (Richins, 1991, p. 17), and have been popularly used in advertising with intention to impact psychologically on the message receiver in the hopes of increasing the ad's effectiveness (Bower, 2001). While marketing literature is replete with evidence of the positive effects of using HAMs in advertising on both ad and product evaluations (Belch et al., 1987; Stephens et al., 1994; Perlini et al., 1999; Yu et al., 2011), support for their effectiveness is somewhat conflicted (Caballero et al., 1989; Bower and Landreth, 2001; Bower, 2001). For instance, Bower (2001) found that HAMs included in advertising could destroy advertising effectiveness because of the deflated self-image in contrast to the beautiful ad models. The power of HAMs in creating negative affect is therefore

\section{Trang 20}


still of interest (Martin and Gentry, 1997; Bower and Landreth, 2001; Bower, 2001; Richins, 1991; Martin and Kennedy, 1993; Heiland et al., 2008).

The effects of physical personal dissatisfaction from exposure and comparison to HAMs are widespread and severe. Experimental studies report that females compared themselves frequently with models in clothing, personal care, and cosmetics ads, and these ads make them feel dissatisfied with their appearance (Richins, 1991). In addition, exposure to highly attractive images could have a negative effect on perceptions of attractiveness of self and others as well as satisfaction with the attractiveness levels of self and others. Continual exposure to highly attractive images could lead to a negative body image, which in turn could lead to eating disorders and mood disorders (Wolf, 1992; Groesz et al., 2002).

The inconsistent support for the use of HAMs in advertising has led researchers to explore the importance of a convergence between the product and the message communicated by a model's image, that is, a model-product type match-up (Kamins, 1990: Kamins and Gupta, 1994; Kahle and Homer, 1985). Although a number of empirical investigations examined the match-up hypothesis suggesting a match between beauty-type and brand image (Solomon et al., 1992), researches did not look at negative effect of HAMs.

Empirical evidence to date has established that the use of HAMs can stimulate comparison behaviors that trigger negative feelings so that negative affect is experienced (Richins, 1991; Martin and Kennedy, 1993; Martin and Gentry, 1997; Heiland et al., 2008). Consequences of such negative affect are confirmed by Bower (2001) in the context of comparison with HAMs resulting reduced advertising effectiveness due to reduced product and model evaluations that in turn cause reduced intention to purchase.
However, in Bower's (2001) research there is a variation in results it may be due to other unmeasured differences.

It is clearly seen that most of the research has focused on the outcomes of negative affect rather than the possible antecedents of negative affect. Research indicates that the negative affective responses to HAMs may be widespread; there is little information about how types of social comparison motives impact on negative affect as a result of exposure to advertising stimuli. And while exposure to advertising has been linked to advertising skepticism in past research (Shigehiro et al., 2004), little has been done to compare such attitudes cross-culturally to advertising skepticism as a result of the socialisation process, as well as the impact of advertising skepticism on negative affect. By controlling for them, it is better able to understand when and why negative affect occurs.

It should, therefore, be concerned with the impact of model type, product type, comparison motive, culture and skepticism on negative affect as an outcome of exposure to advertising including HAMs. The study, in fact, follows recommendations for further research in the area by Bower (2001). The results of this research will help advertisers to have more control regarding selection of HAMs to ensure their beauty type and product type used in advertising contexts will provide positive effect and minimise risk of negative affect. It also allows practitioners to understand cultural impacts and skepticism levels for advertising of HAMs to have a greater impact.

In order to address these issues, the study will begin by summarizing the factors felt to impact an individual's negative affect after exposure to a HAM message source as supported by the literature. 


\section{THEORETICAL BACKGROUND AND HYPOTHESES}

Negative Affect

Negative affect is defined, in this study, as the unpleasant feelings and emotions generated by exposures to HAMs such as negative emotions, moods, feelings and drives and it may include distress, fear anger, disgust, fear and shame (Batra and Ray, 1986). Negative affect occurs here when a HAM has the opposite effect on the audience than was intended. Negative affect has potentially important implications for advertising effectiveness since message recipients would engage in derogation of the HAM featured in the ad causing related advertising messages to lose effectiveness (Bower, 2001). Global affect and discrete affect are two competing perspectives of negative affect. Global negative affect is negative feelings co-occur simultaneously (Edell and Burke, 1987), while discrete one is investigated separately types of negative affect (Batra and Ray, 1986). In this study, global negative affect is considered as an overall measure to investigate types of social comparison motives impact on negative affect as a result of exposure to advertising.

\section{Highly Attractive Model}

Physical beauty has long been celebrated and appreciated by society (Dion et al., 1972). It is useful to note that most of the research on physical attractiveness has been concentrated on facial attractiveness.

The term "HAMs" is used to refer to those who have a beautiful facial appearance (Richins, 1991) and thinness (Striegel-Moore et al., 1986). The appearances of HAMs are both idealized and unrealistic (Bower and Landreth, 2001) and HAMs tend to be associated with the "what is beautiful is good" stereotype. In that stereotype beautiful people are believed to have more positive life outcomes (i.e., more successful careers, better marriages) and are evaluated more positively by others than those who are unattractive (Dion et al., 1972). Conversely, normally attractive models are defined as a more average or moderate weight, height, and facial beauty considered attractive but not beautiful in the idealized manner of HAMs (Bower and Landreth, 2001).

Some studies have examined the role of different ideals or types of beauty in influencing consumers' responses to models in ads (Solomon et al., 1992b; Englis et al., 1994; Heiland et al., 2008). Solomon et al. (1992a) noted that "perceivers distinguish multiple types of good looks, and that in advertising, certain beauty ideals are more appropriately paired with specific products than with others" (p. 23). Correspondingly, Martin and Peters (2005) found that the different types of beauty influence consumers' responses to models in advertising.

For this research, the beauty categories are adopted from Frith et al. (2004) that are defined extracted from Solomon et al.'s (1992) and Englis et al.'s (1994) categories and adapted to Asian context by testing the reliability of the content. Three beauty types include: (1) Classic: slightly older than average, elegant, feminine to look at, fair skin and glamourous, usually wears soft, feminine but not heavily accessorized apparel; (2) Sensual/Sexy: posed in a sexual way, usually wears sexy attire or tight fitting, revealing clothes; and (3) Cute/Girl-Next-Door: with casual attire, a cute and youthful appearance, outdoorsy, in a casual active manner.

Model Characteristics The use of varying beauty types may explain the differences in negative affect as a result of comparison motives that were simulated (Goodman et al., 2008). Bower (2001) noted that the HAM's pose or clothing or the salience of certain HAM physical characteristics [model characteristics] may influence the extent to which negative affect is

Trang 22 
experienced as a result of the comparison. Martin and Gentry (1997) also suggested, when selfimprovement is the primary motive for comparison, self-perceptions of physical attractiveness may temporarily rise in anticipation of an improvement because the comparisons with advertising models are inspiring rather than threatening. When a girl is inspired to improve her physical attractiveness, feelings of self-esteem are likely to be enhanced as well in anticipation of an improvement. It is reasonable to consider ideal beauty types when assessing the affects of a HAM comparison. Therefore, it is hypothesised that:

H1. In high involvement situations, model characteristics will impact on negative affect.

Product Type (Malleability). Product type refers to the extent to which the advertised product improves appearance (Bower, 1997) and malleability (alterability) refers to perceived control over comparison differences (Major et al., 1991). Product type and related body part (malleability) are proposed to influence the level of comparison motives experienced. The nature of the product and related body part is discussed by Bower (2001) and was found by Richins (1991) to impact on negative affect. They argued that when the beauty is achievable the comparer may feel an uplifted (self-improvement motives) and more positive than if the body part is not malleable so that the beauty is desirable but considered unachievable (self-evaluation and self-enhancement motives).

It can be argued that when the body part is malleable or changeable as a result of using the product, then the comparisons may be more optimistic as the body part is alterable so making the level of beauty achievable. A malleable body part is alterable so that reaching a level of beauty is achievable potentially resulting in lower levels of negative affect (Bower, 2001; Yu et al., 2011), whereas non-malleable body parts are not easy to alter potentially resulting in frustration and negative affect. Clearly, the influence of the malleability of a feature's attractiveness may lead to differences in negative affect, thus the hypothesis is suggested:

H2. In high involvement situations, malleability will impact on negative affect.

Comparison Motives. Many studies used (Festinger, 1954) social comparison theory to explain how HAMs in advertising may affect female consumers (Martin and Kennedy, 1993; Martin and Gentry, 1997; Richins 1991; Micu et al., 2012). The basic premise of these studies is that consumers compare their physical attractiveness to HAMs and that these comparisons can have a negative affect on selfperceptions and self-esteem. The importance of physical attractiveness prompts many women to compare themselves with the images of physical perfection, thinness, and beauty found in advertising. A result of that comparison may lead to negative feelings such as frustration and anxiety, because according to (Richins, 1991) exposure to idealized advertising images may change consumers' comparison standards for what they desire or lower perceptions of their own performance on relevant dimensions, the result is lowered satisfaction. Hence it can be seen that exposure to HAMs could have a negative effect on perceptions of attractiveness of self and others as well as satisfaction with the attractiveness levels of self and others.

In the context of advertising, given that advertising models represent an ideal (perhaps unrealistic) image of beauty, the type of comparison that generally occurs will be upward (Martin and Kennedy, 1994). It means females will generally consider advertising models to be superior in terms of physical attractiveness. In this case, any one of the three motives can be served through upward comparisons. However, it is likely that upward comparisons to models in 
ads by females are not self-enhancing, because similarity on surrounding dimensions, such as age or context, are not perceived to exist (Martin and Kennedy, 1994). Thus, when selfenhancement predominates as the motive for comparison, females will most likely avoid upward comparisons to advertising models in an attempt to preserve self-esteem.

Therefore, only self-evaluation and selfimprovement comparison motives are investigated in this research as self-enhancement motives are not naturally occurring. The level of comparison with similar or dissimilar others and the underlying comparison motive is important in understanding negative affect. That is, selfevaluation motive is likely to result in negative affect as the HAM is used as a direct comparison and self-improvement is likely to result in lower rates of negative affect as the HAM is inspirational. It is clearly that the types of comparison motives result in variations of negative feelings. This goes to support the notion that certain types of comparison motivations are more likely to cause negative affect. Therefore, the following hypothesis is generated:

H3. In high involvement situations, comparison motives will have varying impact on negative affect.

Cultural Variation. Culture can be a particularly important consideration for understanding social comparison with HAMs due to each culture having a set of general beliefs about what constitutes conformity and beauty in society. The crucial distinction between individualistic and collectivist cultures is that individualist cultures focus on "I-identity" and personal self-esteem enhancement, while collectivist societies attend more closely to "Weidentity" and social group-esteem maintenance (Hofstede, 2001). While to be feminine in the U.S. (individualist) is to be attractive, deferential, unaggressive, emotional, nurturing, and concerned with people and relationships (Wood, 1999); femininity in Confucian (collectivist) cultures is associated with virtue and modesty (Hofstede, 2001).

Cultural variation may have important implications for social comparison processes (Cynthia, 2004; Donnalyn and Jesica, 2004). These studies found that different cultural background females who were exposed to images of thin models responded differently, for example African American females tend to have a higher level of self-esteem than their Caucasian counterparts. Social comparison theory may suggest that women of various ethnicities respond differently to ideal body images, it can be assumed that negative affect could be varied in different cultures. Thus the following hypothesis is developed:

H4. In high involvement situations, cultural variation will impact on negative affect.

Advertising Skepticism. Obermiller and Spangenberg (1998) defined advertising skepticism as the tendency towards disbelief of advertising claims, which is related to the quality of accumulated consumer experiences. In other words, the more consumers experience perceived advertising deception and exaggeration, the more skeptical they will be. Thus the consumers with relatively higher skepticism toward advertising should exhibit less positive responses to ads. As a result, more skeptical consumers like advertising less, rely on it less, attend to it less (Carl et al., 2005).

As advertising skeptics regard advertising as not credible and therefore not worth processing, negative affect of comparison with HAMs in advertising is likely experienced only when comparers have certain level of belief. Indeed, personal efficacy beliefs do significantly moderate the relationship between personal improvement estimation and the affective consequences of comparison (Bower, 1997). In

Trang 24 
this study, it is expected that the HAMs comparison occurred is likely to result in negative affect in such cases where the comparers have relatively low skepticism towards advertising of HAMs. In other words, those who have high skepticism level towards advertising including HAMs would be unaffected by comparison to produce negative affect, because they may disbelieve advertising in which unattainable beauty ideals (HAMs) appeared to make claims. It could be that with a certain belief of advertising of HAMs would lead to negative feeling result. Therefore:

H5. In high involvement situations, advertising skepticism will impact on negative affect.

Cultural variation may have an impact on skepticism due to conformity and exposure to advertising varying in different culture. It is argued that peer group conformity as discussed is varied significantly cross-culturally was shown to be negatively related to ad skepticism (Mangleburg and Bristol, 1998). For example, Asians are more concerned with peer conformity (being from collectivist societies), one would expect Asians to be relatively less skeptical of advertising (Schaefer et al., 2005). In contrast to collectivist societies, studies in individualistic cultures have shown that Americans generally hold negative attitudes towards advertising (Calfee and Ringold, 1994). Besides, many found that ad skepticism to be positively related to marketplace knowledge (Schaefer et al., 2005; Mangleburg and Bristol, 1998). That is, heavy exposure to advertising has fostered familiarity with advertising tactics and opportunities to test ad truthfulness through their personal purchase experiences.

Because of the positive linkage between conformity, advertising exposure and advertising skepticism, it might be expected that groups with less concerned with peer conformity and greater exposure (i.e., American young females) will be more skeptical. It is clear that it could be expected that such attitudes towards advertising differ across culturally. Therefore the hypothesis is:

H6. In high involvement situations, cultural variation will impact on skepticism towards advertising of HAMs.

\section{METHODOLOGY}

\section{Method}

The method began with an initial pool of approximately 50 HAMs taken from magazines published in Vietnam such as Metropolitan, Her World, The Gioi Thanh Nu, The Gioi Phu Nu, Thoi Trang Tre, Tiep Thi and Gia Dinh, Sai Gon Tiep Thi, etc. The 50 images were then narrowed down to 20 images based on not only level of attractiveness but whether the photograph could be easily manipulated to eradicate the product/brand/copy for each advertisement. Two focus groups comprising of 10 undergraduate females (aged 18-25) in each group were then conducted with the objective being to:

(1) rate the most attractive models of the 20 images of HAMs and determine with beauty type each model belonged to: Cute, Classic, and Sexy;

(2) rate the product malleability of list of products, i.e., lip gloss, teeth whitener, hair straightening gel, etc. and determine whether each product could be classified as malleable or non-malleable; and

(3) rate whether they felt inspired or confronted by several different headlines (based on Martin and Gentry (1997), comparison motives are manipulated through headline) and determine with comparison motive each headline belonged to: self-evaluation, self-improvement.

Result of the focus groups determined the 3 most HAMs that were consistently classified as a single beauty type: Cute, Classic and Sexy. Lip gloss was determined to be a product that 
respondents deemed to be malleable (92\% agreement); skin cleansing bar was deemed to be a non-malleable product ( $94 \%$ agreement). Then the 3 chosen ads containing the HAMs was removed any product, brand, copy. The ads were manipulated to include a generic lip gloss product for each beauty type, a generic cleansing bar for each beauty type, and assessed comparison motive is stimulated by 2 types of headlines (self-evaluation: You. Your Skin/Lips. Think About It. Do You Look This Good?, selfimprovement: Improve Yourself. You Can Learn To Be Just As Beautiful! Looking Better With Skin Fresh Cleansing Bar/Satin Coulors Lip Gloss!) for each type. Twelve manipulations resulted: (1) Cute model, Lip gloss, Selfimprovement; (2) Cute model, Lip gross, Selfevaluation; (3) Cute model, Cleansing bar, Selfimprovement; (4) Cute model, Cleansing bar, Self-evaluation; (5) Classic model, Lip gloss, Self-improvement; (6) Classic model, Lip gross, Self-evaluation; (7) Classic model, Cleansing bar, Self-improvement; (8) Classic model, Cleansing bar, Self-evaluation; (9) Sexy model, Lip gloss, Self-improvement; (10) Sexy model, Lip gross, Self-evaluation; (11) Sexy model, Cleansing bar, Self-improvement; and (12) Sexy model, Cleansing bar, Self-evaluation.

The research methodology was a 3 [beauty types] $\mathrm{x} 2$ [product types] $\mathrm{x} 2$ [comparison motives] between-subjects experimental design. Each respondent, from both domestic and international female undergraduate students studying in international programs and/or universities in Vietnam namely, RMIT University Vietnam, British University Vietnam, The Saigon International University, and University of Social Sciences and Humanities (VNU-HCM) between October 2011 and March
2012, was randomly chosen given a selfadministered questionnaire and a full colour ad of one manipulation only (i.e., one of 12 mentioned above).

\section{Measures}

All measures were assessed through 7-point bipolar semantic differential and/or 7-point Likert-type scales as this is the measure used by most prior studies into social comparison and the idealized images (Martin and Kennedy, 1993; Bower, 2001; Bower and Landreth, 2001; Richins, 1991; Martin and Gentry, 1997). These scales (see Table 2, see more Appendix) were generated on the basis of prior operationalizations. Model attractiveness was measured as much less/much more noticeable, far below/far above average, and 2 Likert-type items (Bower, 2001). Subject comparison with HAM was measured by assessing the degree in which respondents' comparison is through 3 Likert-type items developed and tested by Bower (2001). Product type/malleability was measured by fouritem scale (3 Likert-type items and one semantic differential item). Skepticism towards beauty, advertising and disbelief of claims were measured by 14 Likert-type items (Crossley, 2002; Mangleburg and Bristol, 1998; Boush et al., 1994). Finally, negative affect was measured using the four-item scale developed by Bower (2001).

\section{RESULTS}

A total of 937 usable questionnaires were obtained. A statistical description of the manipulation and sample is shown in Table 1. Accordingly, each manipulation distributed equally and respondents were widely diverse by different age groups, ethnic background, and product involvement

Trang 26 
Table 1. Sample Characteristics

\begin{tabular}{|cc|cc|cc|}
\hline Manipulation & $\mathbf{\%}$ & Beauty Type & $\mathbf{\%}$ & Age & \% \\
1 & 8.0 & Cute & 32.7 & $17-20$ & 51.1 \\
2 & 8.8 & Classic & 34.3 & $21-24$ & 38.3 \\
3 & 8.4 & Sexy & 33.0 & $25-30$ & 8.4 \\
\cline { 3 - 3 } 4 & 7.9 & Comparison & $\mathbf{\%}$ & $31-40$ & 2.2 \\
\cline { 3 - 4 } 5 & 8.0 & Self-evaluation & 49.0 & Ethnicity & $\mathbf{\%}$ \\
6 & 7.9 & Self-improvement & 51.0 & Caucasian & 45.0 \\
\cline { 3 - 4 } 7 & 8.1 & Product Type & $\mathbf{\%}$ & Asian & 48.1 \\
8 & 8.6 & Malleable Lips & 50.7 & Other & 6.9 \\
9 & 8.6 & Non Malleable Skin & 49.3 & & \\
\cline { 3 - 5 } 10 & 8.6 & Involvement & $\mathbf{\%}$ & Bought a similar product as \\
11 & 8.1 & Did buy & 60.2 & featured in ad in the past 2 \\
12 & 9.0 & Did not buy & 39.8 & years & \\
\hline
\end{tabular}

Table 2 shows the results of the Cronbach's alpha reliability measure. No items were omitted as strong results indicate that there is good internal consistency and all the scales had a reliability above 0.6. The Cronbach's alpha measures were all very high which is consistent with previous research in this area.

Table 2. Scale Item, Reliability Test and Overall Measures

\begin{tabular}{|l|l|c|c|c|}
\hline \multicolumn{1}{|c|}{ Construct } & \multicolumn{1}{|c|}{ Scale } & Sig. & Mean & SD \\
\hline Model attractiveness & $\begin{array}{l}\text { Much less/Much more noticeable; } \\
\text { Far below/Far above average; } \\
\text { 2 Likert-type items }\end{array}$ & .838 & 4.46 & 1.040 \\
\hline Subject comparison & 3 Likert-type items & .765 & 4.37 & 1.292 \\
\hline Negative affect & 4 Likert-type items & .873 & 4.17 & 1.349 \\
\hline $\begin{array}{l}\text { Product malleability/ } \\
\text { non-malleability }\end{array}$ & $\begin{array}{l}\text { Not at all influential/Very influential; } \\
\text { 3 Likert-type items }\end{array}$ & .866 & 3.62 & 1.453 \\
\hline Beauty skepticism & 5 Likert-type items & .895 & 4.50 & 1.312 \\
\hline Ad skepticism & 4 Likert-type items & .913 & 2.93 & 1.384 \\
\hline Disbelief of claims & 5 Likert-type items & .871 & 5.07 & 1.158 \\
\hline
\end{tabular}

A series of tests that involve Independent Samples T-test, One-way ANOVA and Correlation are then conducted to test relationships in the research model.

The differences between model characteristics and negative affect were significant, $F(2,929)=25.09, p<.000$. That is, Cute model type $(M=4.47, S D=1.307)$, followed by Sexy model type $(M=4.29, S D=$ 1.368) were the most effective at producing a more negative affect. Cute and Sexy model types were significantly more likely to create a stronger negative affect than Classic model type $(M=$ $3.75, S D=1.271)$. These findings support the expectation that model characteristics impact on negative affect ( $H \mathrm{l}$ is supported). Furthermore, there were significant differences between Classic and Sexy $(p<.000)$, between Classic and Cute $(p<.000)$ with respect to negative affect, while the difference between Sexy and Cute was not significant $(p>.263)$ with respect to negative affect. 
The statistics show that malleable (Lips) ( $M$ $=4.20, S D=1.320)$ created a stronger negative affect than non-malleable (Skin) $(M=4.13, S D=$ 1.379). However, the differences between product types and negative affect were not significant, $t(927)=.840, p>.401$. This indicates that there is no significant difference between the impact of malleable (Lips) and non-malleable (Skin) on negative affect. The findings do not support the expectation that product type/malleability impact on negative affect, $H 2$ is thus rejected.

The differences between social comparison motives and negative affect were significant, $t(928)=3.615, p<.000$. That is, self-evaluation motive had a stronger impact $(M=4.33, S D=$ $1.325)$ than self-improvement motive $(M=4.01$, $S D=1.355)$ on negative affect, so $H 3$ is accepted.

The differences between cultural backgrounds and negative affect were significant, $F(2,917)=17.34, p<.000$. That is, Caucasians had much stronger negative affect $(M=4.46, S D$ = 1.356) than Asians $(M=3.94, S D=1.257)$ when compare themselves with HAMs in advertising. The findings support the expectation that negative affect would be varied in different cultures, $H 4$ is therefore supported.

The results indicate that the relationships between beauty skepticism and negative affect $(r(908)=.065, p<.049)$, between ad skepticism and negative affect $(r(910)=.150, p<.000)$ were significant; however, it was a weak positive relationship. There was no significant difference created by the disbelief of claims on negative affect $(p>.172)$. This means that hypothesis H5 is supported but with limitations.

The statistics also indicate that the differences between cultural backgrounds and all type of skepticism were significant, with beauty skepticism, $F(2,909)=5.86, p<.003$; with ad skepticism $F(2,912)=6.66, p<.001$; and with the disbelief of claims, $F(2,909)=4.601, p<.010$. Overall, the hypothesis $H 6$ that attitudes towards advertising differ across cultures is supported. Besides, there were significant differences between Caucasians and Asians with respect to beauty skepticism $(p<.006)$. That is, Caucasians were more skeptical towards beauty $(M=4.63$, $S D=1.346)$ than Asians $(M=4.35, S D=1.266)$. The relationships between Caucasians and Asians with respect to ad skepticism are significant $(p<.032)$, showing Caucasians were much more skeptical $(M=2.85, S D=1.752)$ than Asians $(M$ $=3.11, S D=1.198)$. Similarly, the relationships between Caucasians and Asians with respect to disbelief of advertising claims were significant $(p<.022)$. It means Caucasians were much disbelieving of advertising claims $(M=5.18, S D$ $=1.199)$ than Asians $(M=4.96, S D=1.191)$.

From the results, it could conclude that five hypotheses are accepted, one rejected (H2) with H5 accepted with limitations.

\section{DISCUSSION}

The unintended consequences of advertising using HAMs are enhanced by this study that some women experience negative affect by comparing themselves with these beauty models. But the study looks further at individual difference variables including beauty type, product type, comparison motive, culture, and ad skepticism.

Analysis reveals that beauty type, and comparison motive have impacts on negative affect. These are consistent with prior researches (Martin and Gentry, 1997; Heidi et al., 1998; Martin and Kennedy, 1994) showing that HAM characteristics may heighten negative affect and explain the differences in negative affect, and motives are demonstrated to influence these differential affective consequences of HAMs in advertising.

In addition, ethnicity and skepticism variables are examined in a social comparison

\section{Trang 28}


theory context by this study. The finding is that both cultural variation and skepticism (and skepticism determined by culture is also confirmed by the interrelationships between them in this study) influence negative affect. This is hence the first study to explore cross-cultural affect of mediated beauty image among Caucasian and Asian young females. The findings are consistent with prior cross-cultural perceptions of ideal body image and advertising skepticism indicating that negative affect could be varied in different cultures (Cynthia, 2004; Donnalyn and Jesica, 2004), as well as more skeptical consumers experience negative affect less (Carl et al., 2005). Specifically, Caucasians display a greater negative affect and more skeptical towards advertising than their Asians counterpart. These findings are actually important to issues related to standardization of cross-cultural advertising. That is, consumer perceptions of messages communicated through visual elements of ads can be especially challenging due to the potential to communicate unintended meanings.

Although this study investigates some cultural specifications regarding negative affect, it still does not state about those from Caucasians or Asians who are more motivated by certain comparison motive and who view the self as more malleable and improvable than other. Also the findings demonstrate the need to look beyond measures of advertising knowledge and product type again towards negative affect to study the impact of HAMs in advertising more fully.

\section{CONCLUSION}

The research investigating what limiting conditions make comparers turn negative contributes a number of practical implications. Firstly, it identifies that model characteristics has an impact on negative affect despite product type does not, suggesting that HAM characteristics is ad stimulus that influences the extent to which negative affect is experienced as a result of the comparison. By understanding this knowledge practitioners can control the ad stimuli to lessen the unintended consequences of HAMs. Secondly, the role of motives for comparison is found in this study that it is responsible for the variation in negative affect. With self-evaluation motive it has a stronger impact than selfimprovement one on negative affect indicating that the extent to which a young female believes that she might be able to improve her appearance may prompt a self-improvement motivation. By manipulating the comparison motive, in certain conditions, a HAM comparison will occur and the affective consequences of those comparisons may be controlled. In addition, in relation to cultural variation and skepticism, the finding is that they have impacts on negative affect of a HAM comparison. The research also finds that there are interrelationships between culture and skepticism can help international marketers to understand whether consumers across various cultural markets identify with specific images in an ad, especially possible cross-cultural differences in consumer attitudes of HAMs stimuli in advertising elements. Besides, the results of the correlation indicate that skepticism towards beauty and advertising are related to negative affect. This is an important finding to management as it suggests that in the case of advertising seen as skeptical there needs to be controlled for them. In all, the study can help managers to maximise the effect of HAMs in advertising by understanding how type of comparison motives, model characteristics, cultural variation as well as skepticism impact on negative affect. By isolating them it will inform managers about when and why negative affect arises to have a greater impact.

While this study offers a foundation for further hypothesis testing in the area of crosscultural skepticism research, data gathering 
limitation must be considered. That is, because all respondents are university female students, education levels of this sample may be above average. Findings among varied social-economic strata may reveal different results. As per Boush et al. (1993), trust in advertising decreases as one's educational level increases. It would be of interest to look further into negative affect as a result of HAMs comparison held by people of varying ages, for example, to learn how representative samples of young female adults other than university female students would score on negative affect. A longitudinal study would also be beneficial in determining whether negative affect of HAMs comparison actually change over time.

\section{APPENDIX}

\section{Measures}

\begin{tabular}{|r|c|c|c|c|c|c|}
\hline $\begin{array}{c}\text { Strongly } \\
\text { Disagree }\end{array}$ & Disagree & $\begin{array}{c}\text { Slightly } \\
\text { Disagree }\end{array}$ & Neutral & $\begin{array}{c}\text { Slightly } \\
\text { Agree }\end{array}$ & Agree & $\begin{array}{r}\text { Strongly } \\
\text { Agree }\end{array}$ \\
\hline 1 & 2 & 3 & 4 & 5 & 6 & 7 \\
\hline
\end{tabular}

\section{Model attractiveness:}

- Relative to female models seen in advertising, this model's beauty makes her:

\begin{tabular}{|l|l|l|l|}
\hline Much less noticeable & & & Much more noticeable \\
\hline
\end{tabular}

- Compared to other female models I normally see in advertisements, this model's beauty is:

Far below average

Far above average

- This model's superior beauty would stand out among other models in a magazine.

\begin{tabular}{|c|c|c|c|c|c|c|}
\hline 1 & 2 & 3 & 4 & 5 & 6 & 7 \\
\hline
\end{tabular}

- This model reflects somebody who I think is beautiful.

\begin{tabular}{|c|c|c|c|c|c|c|}
\hline 1 & 2 & 3 & 4 & 5 & 6 & 7 \\
\hline
\end{tabular}

\section{Subject comparison:}

- I think that most of my friends would compare themselves to the model in the advert.

\begin{tabular}{|c|c|c|c|c|c|}
\hline 1 & 2 & 3 & 4 & 5 & 6 \\
\hline
\end{tabular}

7

- If you noticed this advertisement in a magazine filled with images of highly attractive models, how likely is it that you would compare yourself to the model?

Extremely unlikely Extremely likely

- If the average woman interested in using this type of product noticed this advertisement, how likely is it that she would compare herself to the model?

\begin{tabular}{|l|l|l|l|l|}
\hline Extremely unlikely & & & Extremely likely \\
\hline
\end{tabular}

\section{Negative affect:}

- Sometimes, I feel resentful when I encounter advertisements like this one:

\begin{tabular}{|l|l|l|l|l|l|l|}
\hline 1 & 2 & 3 & 4 & 5 & 6 & 7 \\
\hline
\end{tabular}

- Advertisements such as this one sometimes make my feel anxious about my appearance.

\begin{tabular}{|l|l|l|l|l|l|l|}
\hline 1 & 2 & 3 & 4 & 5 & 6 & 7 \\
\hline
\end{tabular}

- Advertisements like this can sometimes negatively influence how I feel about myself.

\begin{tabular}{|c|c|c|c|c|c|c|}
\hline 1 & 2 & 3 & 4 & 5 & 6 & 7 \\
\hline
\end{tabular}

- Advertisements like this one sometimes make me feel frustrated.

\begin{tabular}{|l|l|l|l|l|l|l|}
\hline 1 & 2 & 3 & 4 & 5 & 6 & 7 \\
\hline
\end{tabular}

\section{Trang 30}




\section{Product malleability/non-malleability:}

- If a typical person used this product, it would be responsible for improvements in the users' beauty.

\begin{tabular}{|l|l|l|l|l|l|l|}
\hline 1 & 2 & 3 & 4 & 5 & 6 & 7 \\
\hline
\end{tabular}

- How influential do you believe the advertised product was in improving the model's appearance?

Not at all influential

Very influential

- I believe that the advertised product positively affected the model's beauty.

Telieve that the advertised product positively affected the model's beauty.

\begin{tabular}{|l|l|l|l|l|l|l|}
1 & 2 & 3 & 4 & 5 & 6 & 7 \\
\hline
\end{tabular}

- The model is more beautiful as a result of her use of the advertised product.

\begin{tabular}{|l|l|l|l|l|l|l|}
\hline 1 & 2 & 3 & 4 & 5 & 6 & 7 \\
\hline
\end{tabular}

\section{Beauty skepticism:}

\begin{tabular}{|c|c|c|c|c|c|c|c|}
\hline $\begin{array}{l}\text { - I'm sick and tired of being told what beauty products are } \\
\text { going to make me look better. }\end{array}$ & 1 & 2 & 3 & 4 & 5 & 6 & 7 \\
\hline $\begin{array}{l}\text { - I've been told so many products are going to make us } \\
\text { more attractive, I don't take much notice any more. }\end{array}$ & 1 & 2 & 3 & 4 & 5 & 6 & 7 \\
\hline $\begin{array}{l}\text { - There are so many adverts featuring attractive models } \\
\text { that I tend not to take notice of them any more. }\end{array}$ & 1 & 2 & 3 & 4 & 5 & 6 & 7 \\
\hline $\begin{array}{l}\text { - There is so much information about cosmetics that it is } \\
\text { difficult to know what to believe anymore. }\end{array}$ & 1 & 2 & 3 & 4 & 5 & 6 & 7 \\
\hline $\begin{array}{l}\text { - On the whole, I am sceptical about advertisements with } \\
\text { cosmetic products telling me that the product will make } \\
\text { me look good. }\end{array}$ & 1 & 2 & 3 & 4 & 5 & 6 & 7 \\
\hline \multicolumn{8}{|l|}{ Ad skepticism: } \\
\hline - Magazine ads tell the truth. & 1 & 2 & 3 & 4 & 5 & 6 & 7 \\
\hline $\begin{array}{l}\text { - You can believe the things that people say in adverts } \\
\text { say or do. }\end{array}$ & 1 & 2 & 3 & 4 & 5 & 6 & 7 \\
\hline $\begin{array}{l}\text { - The products advertised in magazines are always the } \\
\text { best products to buy. }\end{array}$ & 1 & 2 & 3 & 4 & 5 & 6 & 7 \\
\hline $\begin{array}{l}\text { - If a magazine ad was not true it wouldn't be printed in a } \\
\text { magazine. }\end{array}$ & 1 & 2 & 3 & 4 & 5 & 6 & 7 \\
\hline \multicolumn{8}{|l|}{ Disbelief of claims: } \\
\hline $\begin{array}{l}\text { - Advertisers care more about getting you to buy things } \\
\text { than what is good for you. }\end{array}$ & 1 & 2 & 3 & 4 & 5 & 6 & 7 \\
\hline $\begin{array}{l}\text { - I often notice tricks that advertisers play to try and get } \\
\text { me to do something. }\end{array}$ & 1 & 2 & 3 & 4 & 5 & 6 & 7 \\
\hline $\begin{array}{l}\text { - Magazine adverts try to make people buy things that } \\
\text { they don't really need. }\end{array}$ & 1 & 2 & 3 & 4 & 5 & 6 & 7 \\
\hline $\begin{array}{l}\text { - Magazine adverts tell only the good things about their } \\
\text { product, they don't tell you the bad things. }\end{array}$ & 1 & 2 & 3 & 4 & 5 & 6 & 7 \\
\hline $\begin{array}{l}\text { - Magazine adverts are all about the same when it comes } \\
\text { to telling the truth. }\end{array}$ & 1 & 2 & 3 & 4 & 5 & 6 & 7 \\
\hline
\end{tabular}




\section{Người mẫu cực hấp dẫn trong quảng cáo: điều gì gây nên hiệu ứng tiêu cực?}

\section{- Nguyễn Hoàng Sinh}

\section{Trường ĐH Mở TPHCM}

\section{TÓM TÁT:}

Người mẫu cực hấp dẫn đã được sử dụng rộng rãi trong quảng cáo để gây ảnh hưởng về tâm lý đối với người nhận thông điệp trong nỗ lực gia tăng hiệu quả của quảng cáo. Tài liệu nghiên cứu về tiếp thị ghi nhận rất nhiều bằng chứng về hiệu ứng tích cực của việc sử dụng những người mẫu nhu thế. Tuy nhiên, ý kiến về hiệu quả của cách làm này lại it nhiều trái ngược nhau. Nghiên cứu này nhằm đóng góp vào khối kiến thức chung về vấn đề trên thông qua khảo sát tác động của các biến về khác biệt cá nhân (đặc điểm của người mẫu, loại sản phẩm, động cơ so sánh và văn hóa) lên hiệu ứng tiêu cực. Nghiên cứu cũng tìm hiểu liệu tính hoài nghi với quảng cáo do nền văn hóa định hình có ảnh hưởng gì đến hiệu ứng tiêu cực xuất phát từ việc so sánh với người mẫu trong quảng cáo không? Nghiên cứu sử dụng một thiết kế thử nghiệm giữa các đối tượng gồm 3 [mẫu nhan sắc] x 2 [loại sản phẩm] x 2 [động cơ so sánh]. Mẫu nghiên cứu là nữ sinh viên đa văn hóa đang theo học những chương trình và đại học quốc tế tại VN. Kết quả nghiên cứu ủng hộ hầu hết các giả thuyết; chỉ có biến loại sản phẩm không có tác động. Nghiên cứu cũng thừa nhận rằng có mối tương quan giữa biến văn hóa và tính hoài nghi trong quảng cáo. Những phát hiện này có nhiều hàm ý cho người làm quảng cáo, nhà nghiên cứu và nhà hoạch định chính sách về ảnh hưởng tiêu cực có thể có từ việc sử dụng người mẫu cực hấp dẫn trong quảng cáo.

Từ khóa: hiệu ứng tiêu cực, mẫu nhan sắc, loại sản phẩm, động cơ so sánh, xuyên văn hóa, tính hoài nghi với quảng cáo

\section{REFERENCES}

[1]. Batra, R. and Ray, M.L., Affective Responses Mediating Acceptance of Advertising, Journal of Consumer Research 13(2), 234-249, (1986).

[2]. Belch, G.E., Belch, M.A. and Villareal, A., Effects of Advertising Communications: Review of Research, Research in Marketing 9, (1987).

[3]. Boush, D.M., Friestad, M. and Rose, G.M., Adolescent Skepticism toward TV Advertising and Knowledge of Advertiser
Tactics, Journal of Consumer Research 21(1), 165-175, (1994).

[4]. Bower, A.B., Understanding Comparisons to the Idealized Images in Advertising: Antecedents, Affective Consequences and Product Implications, University of South Carolina, South Carolina, (1997).

[5]. Bower, B.A., Highly Attractive Models in Advertising and the Women Who Loathe Them: The Implications of Negative Affect

Trang 32 
for Spokesperson Effectiveness, Journal of Advertising 30(3), 51-63, (2001).

[6]. Bower, B.A. and Landreth, S., Is Beauty Best? Highly Versus Normally Attractive Models in Advertising, Journal of Advertising 30(1), 1-12, (2001).

[7]. Caballero, M.J., Lumpkin, J.R. and Madden, C.S., Using Physical Attractiveness as an Advertising Tool: An Empirical Test of the Attraction Phenomenon, Journal of Advertising Research 29(4), 16-22, (1989).

[8]. Calfee, J.E. and Ringold, D.J., The Seventy Percent Majority: Enduring Consumer Beliefs about Advertising, Journal of Public Policy and Marketing 13(2), 228-238, (1994).

[9]. Carl, O., Eric, S. and Douglas, L.M., Ad Skepticism: The Consequences of Disbelief, Journal of Advertising 34(3), 7-17, (2005).

[10].Crossley, M.L., Resistance to Health Promotion: A Preliminary Comparative Investigation of British and Australian Students, Health Education 102(6), 289-299, (2002).

[11].Cynthia, M.F., Does Race Matter? Effects of Idealized Images on African American Women's Perceptions of Body Esteem, Journal of Black Studies 34(3), 323-347, (2004)

[12].Dion, K.K., Berscheid, E. and Walster, What Is Beautiful Is Good, Journal of Personality and Social Psychology 24(3), 285-290 (1972)

[13].Donnalyn, P., Jesica, K., Cross-CulturalGenerational Perceptions of Ideal Body Image: Hispanic Women and Magazine Standards, Journalism and Mass Communication Quarterly 81(1), 89-107, (2004).

[14].Edell, J. A., Burke, M.C., The Power of Feelings in Understanding Advertising Effects, Journal of Consumer Research 14(3), 421-433 (1987).
[15].Englis, B.G., Solomon, M.R., Ashmore, R.D. Beauty Before the Eyes of Beholders: The Cultural Encoding of Beauty Types in Magazine Advertising and Music Television, Journal of Advertising 23(2), 49-64, (1994).

[16].Festinger, L., A Theory of Social Comparison Processes, Human Relations 7, 117-140, (1954).

[17].Frith, K.T., Cheng, H. and Shaw, P., Race and Beauty: A Comparison of Asian and Western Models in Women's Magazine Advertisements, Journal of Sex Roles 50(12), 53-61, (2004).

[18].Goodman, J. R., Morris, J. D. and Sutherland, J. C., Is beauty a joy forever? Young women's emotional responses to varying types of beautiful advertising models, Journalism \& Mass Communication Quarterly 85(1), 147-168, (2008).

[19].Groesz, L.M., Levine, M.P., and Murnen, S.K., The Effect of Experimental Presentation of Thin Media Images on Body Satisfaction: A Meta-Analytic Review, International Journal of Eating Disorders 31, 1-16, (2002).

[20].Heiland, T. L., Murray, D. S. and Edley, P. P., Body image of dancers in Los Angeles: the cult of slenderness and media influence among dance students, Research in Dance Education 9(3), 257-275, (2008).

[21].Hofstede, G., Culture's Consequences: Comparing Values, Behaviors, Institutions, and Organizations across Nations (2nd edn), Sage Publications, Thousand Oaks, California, (2001).

[22].Kahle, L.R. and Homer, P.M., Physical Attractiveness of the Celebrity Endorser: A Social Adaptation Perspective, Journal of Consumer Research 11(4), 954-964, (1985).

[23].Kamins, M.A., An Investigation into the 'Match-Up' Hypothesis in Celebrity Advertising, Journal of Advertising 19(1), 413, (1990). 
[24].Kamins, M.A. and Gupta, K., Congruence between Spokesperson and Product Type: A Matchup Hypothesis Perspective, Psychology and Marketing 11(6), 569-586, (1994).

[25].Major, B., Testa, M., and Bylsma, W.H., Response to Upward and Downward Comparisons: The Impact of Esteem Relevance and Perceived Control, in Suls, J. and Wills, T.A. (eds), Social Comparison: Contemporary Theory and Research, Erlbaum, Hillsdale, NJ, 237-260, (1991).

[26].Mangleburg, T.F. and Bristol, T., Socialization and Adolescents' Skepticism toward Advertising, Journal of Advertising 27(3), 11-21, (1998).

[27].Martin, C. M. and Peters, C.O., Exploring Adolescent Girls' Identification of Beauty Types through Consumer Collages, Journal of Fashion Marketing and Management 9(4), 391-406, (2005).

[28].Martin, C.M. and Gentry, W.J., Stuck in the Model Trap: The Effects of Beautiful Models in Ads on Female Pre-Adolescents and Adolescents, Journal of Advertising 26(2), 19-34, (1997).

[29].Martin, C.M. and Kennedy, F.P., Advertising and Social Comparison: Consequences for Female Preadolescents and Adolescents, Psychology and Marketing 10(6), 513-530, (1993).

[30].Micu, C. C. and Coulter, R., The Effect of Attractiveness in Advertising and Comparison Motives on Self-Judgments and Product Evaluations: A Cross-National Perspective, Journal of International Consumer Marketing 24(1-2), 79-99, (2012).

[31].Obermiller, C. and Spangenberg, E., Development of a Scale to Measure Consumer Skepticism toward Advertising, Journal of Consumer Psychology 7, 159-186, (1998).
[32].Perlini, A., Bertolissi, S. and Lind, D., The Effects of Women's Age and Physical Appearance on Evaluations of Attractiveness and Social Desirability, Journal of Social Psychology 139, 343-354, (1999).

[33].Richins, M.L., Social Comparison and the Idealized Images of Advertising, Journal of Consumer Research 18(1), 71-83, (1991).

[34].Schaefer, D.A., Hermans, C.M. and Parker, R.S., A Cross-Cultural Exploration of Advertising Skepticism and Media Effects in Teenagers, Marketing Management Journal 15(2), 29-42, (2005).

[35].Shigehiro, O., Ed, D., Scollon, C.N. and Biswas-Diener, R., Cross-Situational Consistency of Affective Experiences across Cultures, Journal of Personality and Social Psychology 86(3), 460-472, (2004).

[36].Solomon, M.R., Ashmore, R.D. and Longo, L.C., The Beauty Match-Up Hypothesis: Congruence between Types of Beauty and Product Images in Advertising, Journal of Advertising 21(4), 23-34, (1992).

[37].Stephens, D., Hill, R. and Hanson, C., The Beauty Myth and Female Consumers: The Controversial Role of Advertising, Journal of Consumer Affairs 28(1), 137-153, (1994).

[38].Striegel-Moore, R.H., Silberstein, L.R. and Rodin, J., Toward an Understanding of Risk Factors for Bulimia, American Psychologist 41, 246-263, (1986).

[39].Wolf, N., The Beauty Myth: How Images of Beauty Are Used Against Women, Anchor Books, New York, (1992).

[40].Wood, J., Communication, Gender and Culture (3rd edn), Wadsworth, Belmont, CA, (1999).

[41].Yu, U. J., Damhorst, M. L. and Russell, D. W., The Impact of Body Image on Consumers' Perceptions of Idealized Advertising Images and Brand Attitudes, Family and Consumer Sciences Research Journal 40(1), 58-73, (2011).

\section{Trang 34}

